Thermal Science and Engineering (2018) Volume 1 doi: $10.24294 /$ tse.v1i2.375

\title{
Numerical Investigation of Flow Boiling Heat Transfer in Helically Coiled Tube under Constant Heat Flux
}

\author{
Mohammad Ali Abdous*, Shahriyar Ghazanfari Holagh, Hamid Saffari
}

Iran University of science and technology, Tehran, Iran, m.a.abdous@gmail.com

\begin{abstract}
Numerical study of subcooled and saturated flow boiling in the curved and helically coiled tubes in presence of phase change is one of the challenging area of CFD studies. In this paper, the CFD modeling of the nucleate and convective flow boiling in the small helically coiled tube at low vapor quality (up to the 18.93 percent) region is studied. A proper Eulerian-based mathematical model is used for interphase exchange forces and heat transfer between two phases in CFD modeling using Bulk boiling model. The results show that, the inner and the bottom wall of the helically coiled tube have the lowest and the highest heat transfer coefficient, respectively. The effect of change in coil diameter, helical pitch and tube diameter is investigated on the counters of vapor volume fraction. It is seen that at low vapor quality flows, the heat transfer coefficient is enhanced by decreasing in coil diameter, tube diameter and increasing in coil pitch of helically coiled tube.
\end{abstract}

Keywords: Computational fluid dynamic (CFD); helically coiled tube; boiling heat transfer coefficient; void fraction; pressure drop

\section{Introduction}

Flow boiling inside helically coiled tubes is one of the most common and efficient heat transfer mechanisms in heat exchangers due to geometrical structure of these tubes. Some phenomena such as inhomogeneous phase distribution, secondary flow and radial pressure gradient affect hydro-thermal design conditions ${ }^{[1]}$. These tubes have wide applications in two-phase flow systems such as air-conditioning and refrigeration systems, power generation, water purification systems, chemical reactors, food industries, heat recoveries and mixers and etc. ${ }^{[1,2]}$

In recent years, the advances in computational technologies have allowed flow boiling simulations faster than before. Generally, according to the problem specifications, objectives and characteristics, there are some important models for numerical simulation of two-phase flow and boiling heat transfer in channels. Most often, numerical study of two-phase flow is based on Eulerian- Eulerian (EE) mathematical approach. This approach considers the liquid phase as a continuum phase and the particles phase (vapor bubbles in boiling flow) as another continuum phase. Then, the conservation equations are solved by considering interphase forces and exchanged heat on a control volume for both of phases. ${ }^{[3-5]}$

The literature review shows that in straight tubes, one of the most frequently used methods in modelling the subcooled flow boiling is based on the so-called RPI wall boiling model introduced first by Kurul \& Podowski ${ }^{6]}$. It must be mentioned that, this model has been mostly used to simulate the subcooled nucleate boiling in straight pipes. The investigation of water flow boiling in a circular pipe was performed by Koncar et.al with CFX-4.3 code ${ }^{[7]}$. In their study, the effect of using different models for interphase forces except drag force (non-drag forces), the bubble diameter, and the bubble-induced turbulence were studied. They assumed different bubble diameter formulas to achieve the correct prediction of void fraction in accordance with the experimental results of Bartel ${ }^{[8]}$ at low pressure. Numerical study of flow boiling was conducted by Li et.al ${ }^{[9]}$ who used the RPI wall boiling model to simulate the flow boiling of nitrogen in $6 \mathrm{~mm}$ diameter vertical tube with constant mass velocity and variable wall heat flux. The CFX-4.3 code was modified using the new correlations for interfacial transfer terms in order to match better with experimental data for vapor volume fraction and pressure drop. Chen et.al ${ }^{[10]}$ investigated upward subcooled flow boiling of R-113 based on a 
modified two-fluid model with RPI wall boiling model in a vertical concentric annulus using CFX-10 code with an extended user defined FORTRAN code. They studied effect of temperature dependent properties and saturation temperature variation on CFD simulation results and compared the results with experimental data conducted by R.P.Roy and S.Kang ${ }^{[11,12]}$ and previous results predicted by Koncar et a ${ }^{[13]}$. They concluded that, their modified model have better approximation with the experimental data in comparison with Koncar et a ${ }^{[13]}$. S.Abishek et.a[ ${ }^{[14]}$ preformed a numerical flow boiling simulation for FC-72 fluid, in double-pipe evaporator under atmospheric pressure conditions with ANSYS-FLUENT 14.0 code. They employed Eulerian two-fluid model and RPI model with SST k $-\omega$ turbulent model for two-phase flow boiling simulation and compared the numerical results with the experimental results of vapor volume fraction by Zeitoun and Shoukri ${ }^{[15]}$ and heat transfer coefficients by Kommer ${ }^{[16]}$. Sun et.a[ ${ }^{[17,18]}$ proposed a proper vapor-liquid phase change model for two-phase flow boiling and with VOF method in FLUENTcode. They verified this model with one-dimensional Stefan problem that used as a benchmark problem for testing the developed model $^{[19-21]}$ and two-dimensional film boiling problem ${ }^{[20-22]}$. The results simulated by their model were matched with the analytical solutions and calculation results by some other researchers ${ }^{[19,20,23]}$ and $\mathrm{Mao}^{[24]}$. Their model is precise and applicable in FLUENT code.

One of the important steps in two-phase turbulent flow boiling CFD simulation is choosing a suitable turbulent model. The effect of different turbulent models ( $\mathrm{k}-\varepsilon$ model and $\mathrm{k}-\omega$ model) on subcooled flow boiling simulation in vertical tube with FLUENT 14.5 code was studied by Zhang.et.al ${ }^{[25]}$. They employed a two-fluid model coupled with RPI wall boiling model and studied performances of different turbulent models, wall functions and two-phase turbulence treatments based on four sets of grids. Comparison of their results with Bartolemei experimental data $^{[26,27]}$ demonstrated that $\mathrm{k}-\varepsilon$ turbulent model is more compatible with experimental results.

Flow boiling in helically and bended pipes is one of the complicated cases for numerical study. The coexistence of phase change and centrifugal phenomenon in these tubes make the complexity in numerical analysis of flow boiling. For flow boiling simulation in curved pipes, the literature review shows that flow boiling of R141b fluid in horizontal serpentine tube was investigated by Yang et.a[ ${ }^{[28]}$ using VOF model. The experiment is performed under atmospheric pressure at different heat fluxes. They studied flow patterns along the channel including bubbly, churn, slug and wavy flows. The results showed that, the VOF model is capable of predicting the different flow patterns in straight parts. In the curved parts, this prediction is not exact due to the mixing of two phases by centrifugal characteristic of flow in the bend. Nadim ${ }^{[2]}$ simulated the subcooled flow boiling in 90 degree bend tube using a non-equilibrium model for flow boiling simulation with FLUIENT code. He compared the obtained numerical results with the experimental ones of void fraction by Pierre and Bankoff ${ }^{[30]}$. Wu et.al ${ }^{[31]}$ performed an experimental and numerical simulation to investigate flow boiling of refrigerant R-141b in a horizontal serpentine tube under at atmospheric pressure. They used Eulerian two-fluid model and Bulk boiling model with Realizable $\mathrm{k}-\varepsilon$ turbulent model for numerical simulation. Comparison of their numerical and experimental results shows a good agreement with each other. Aminfar et. al ${ }^{[32]}$ modeled the subcooled flow boiling in a curved annuli tube and compared the results with the experimental data of Lee et. $a 1^{[33]}$. They employed Eulerian two-fluid model and wall boiling model (RPI) with $\mathrm{k}-\omega$ turbulent model for numerical simulation. Jo $e t$. $a l^{[34]}$ conducted subcooled flow boiling study of a helically coiled tube in steam generator heat exchangers using Eulerian two-fluid model with CFX-5.7 code. In their research, two models including RPI wall boiling model and Bulk boiling were compared with each other for simulation of boiling in vertical tube. They concluded that the Bulk boiling model could predict the void fraction in straight tubes better than that of RPI wall boiling model. Therefore, the Bulk boiling model was applied to simulate flow boiling in the helically coiled tube. In their paper, they compared the trend of the heat transfer coefficient in different peripheral angles with Owhadi et.al[35] experimental results.

D. Colorado-Garrido et.al ${ }^{[36,37]}$ developed a one-dimensional computational method based on finite volume by discretization of continuity, momentum and energy equations and coupling them with implicit step by step method to investigation of heat transfer and fluid dynamic behavior for water flow boiling in a helically double-pipe vertical 
evaporator. They verified the proposed model with experimental data base provided by L.Santini ${ }^{[38]}$ and Santoyo-Castelazo and Siqueiros ${ }^{[39]}$ on pressure drop.

The occurrence of boiling in a flow affects its hydrodynamic characteristics significantly. The phase change phenomenon results in instabilities and intense turbulence due to the drastic increase in mixture velocity of fluid. These changes strengthen the interphase exchanges in saturated flow boiling condition. Published numerical studies on saturated flow boiling are significantly fewer than subcooled flows. One of the main reasons is the highly complicated and instable nature of flows in saturated flow boiling with respect subcooled one. The intense velocity and temperature gradients in saturated flow boiling make its modeling much more difficult, requiring much slower computational process (smaller time steps during modeling process) in order to avoid divergence in numerical results. In vertical helically coiled tube, the complexity in simulation of saturated flow boiling explained above, mixed with the secondary flow generated by the curvature and torsion of this tube.

The literature review shows there are few numerical studies conducted on subcooled and specially saturation flow boiling in helically coiled tubes. Also effect of geometrical parameters such as coil diameter, coil pitch and tube diameter, has not investigated on vapor volume fraction and heat transfer coefficient up to now.

The main objective of this paper is simulation of flow boiling in a small helically coiled tube at low vapor qualities (including subcooled and saturation flow boiling up to 18.93 percent vapor qualities). Proper mathematical formulation is presented in order to obtain this goal. The mathematical model is based on Eulerian two-fluid model for subcooled flows successfully applied to low vapor quality region as well as subcooled one with Bulk boiling model which recommended by Jo et. $a 1^{[34]}$. The results of this model are validated against Cioncoilini et. al[40] with acceptable compatibility. Finally, the effects of coil diameter, coil pitch and tube diameter are discussed on vapor volume fraction and heat transfer coefficient.

\section{Physical model and mathematical formulation}

In the experimental work presented by Cioncolini et. ${ }^{\text {al. }[40]}$ the "coil 1" considered which had tube diameter of 4.98 $\mathrm{mm}$, coil diameter of $130 \mathrm{~mm}$, and coil pitch of $40.3 \mathrm{~mm}$. It must be mentioned that, the heated length of the helically coiled tube in simulation was $820 \mathrm{~mm}$. The schematic figure of experimental work is shown in Figure1.

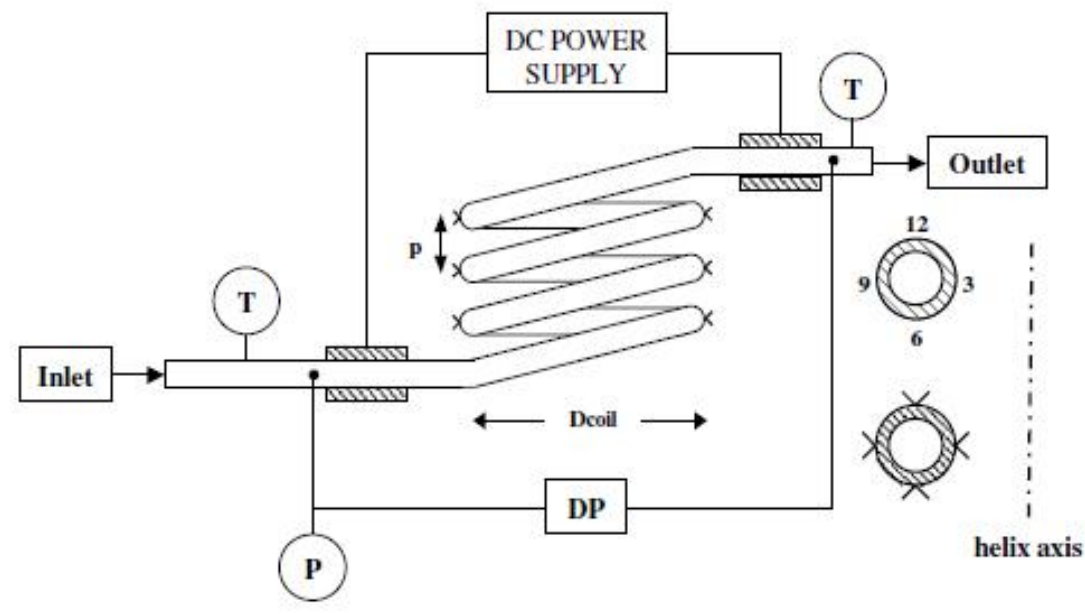

Figure 1; The schematic figure of Cioncolini et.al experimental test ${ }^{[40]}$.

The simulated geometry for numerical analysis is represented in Figure 2. Cioncoilini et. al. ${ }^{[40]}$ considered four turns of helically coiled tube in their experiments but, in this study two turns of helically coiled tube is considered for CFD simulations. The working fluid is water and the test pressures are between two to five times of the atmospheric pressure. In each test, subcooled water enters a $30 \mathrm{~cm}$ long adiabatic straight channel to ensure the fully developed hydrodynamic condition at helically coil entrance. Then, the flow runs through vertical helically coiled tube with constant and uniform wall heat flux. The subcooled boiling begins at the position where the value of the wall 
temperature reaches water saturation point. The flow reaches the saturation temperature with further advance in the heated coil, and saturated flow boiling begins. Finally, the flow exits from $30 \mathrm{~cm}$ long adiabatic straight channel.
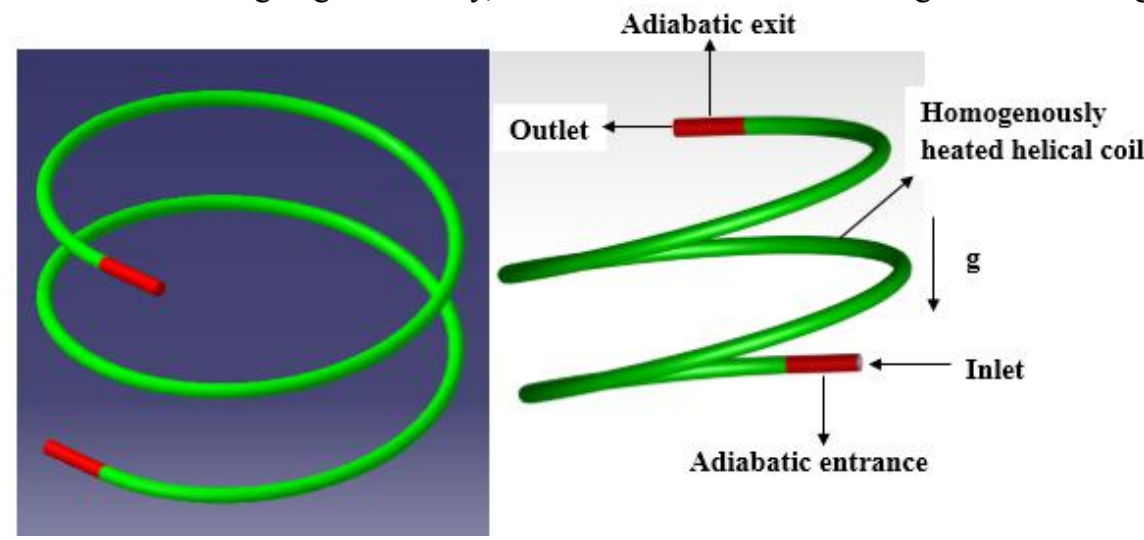

Figure 2; The schematic figure of boundary conditions implied on coil geometry.

The governing equations include the continuity, momentum, energy and turbulence equations. These equations are solved for each phase separately, and added by some expressions to include the effects of interphase exchanges. The governing equations are as follows:

\subsection{Continuity equation}

The continuity equation for liquid phase (l) and vapor phase (v) is written as;

$$
\frac{\partial}{\partial \mathrm{t}}\left(\alpha_{\mathrm{l}} \rho_{\mathrm{l}}\right)+\nabla \cdot\left(\alpha_{1} \rho_{\mathrm{l}} \overrightarrow{\mathrm{u}}_{\mathrm{l}}\right)=\sum_{\mathrm{v}=1}^{\mathrm{n}}\left(\dot{\mathrm{m}}_{\mathrm{vl}}-\dot{\mathrm{m}}_{\mathrm{lv}}\right)
$$

Where, $\alpha_{1}$ and $\overrightarrow{\mathrm{u}}_{\mathrm{l}}$ are the volume fraction and the velocity of the 1 phase, $\dot{\mathrm{m}}_{\mathrm{vl}}$ and $\dot{\mathrm{m}}_{\mathrm{lv}}$ represent the mass transfer between 1 and $v$ phases. The following equation is solved for each computational cell to connect the volume fractions of two phases together:

$$
\sum_{\mathrm{q}=1}^{\mathrm{n}} \alpha_{1}=1
$$

\subsection{Momentum equation}

The general form of momentum equation is like that of single phase flows, altered by additional terms to account for interphase forces. In this study, the additional terms for drag force and wall lubrication one proved to be necessary: $\frac{\partial}{\partial \mathrm{t}}\left(\alpha_{1} \rho_{\mathrm{l}} \overrightarrow{\mathrm{u}_{1}}\right)+\nabla \cdot\left(\alpha_{1} \rho_{\mathrm{l}} \overrightarrow{\mathrm{u}}_{\mathrm{l}} \overrightarrow{\mathrm{u}}_{\mathrm{l}}\right)=-\alpha_{1} \nabla \mathrm{p}+\nabla \cdot \overline{\mathrm{\tau}}_{1}+\alpha_{\mathrm{l}} \rho_{\mathrm{l}} \overrightarrow{\mathrm{g}}+\sum_{\mathrm{v}=1}^{\mathrm{n}}\left(\overrightarrow{\mathrm{R}}_{\mathrm{vl}}+\dot{\mathrm{m}}_{\mathrm{vl}} \overrightarrow{\mathrm{u}}_{\mathrm{vl}}-\dot{\mathrm{m}}_{\mathrm{Iv}} \overrightarrow{\mathrm{u}}_{\mathrm{lv}}\right)+\left(\overrightarrow{\mathrm{F}}_{\mathrm{WL}, \mathrm{l}}+\overrightarrow{\mathrm{F}}_{\mathrm{LIFT,1}}+\mathrm{F}_{\mathrm{TD}, \mathrm{l}}\right)$

$\overrightarrow{\mathrm{F}}_{\mathrm{WL}, \mathrm{q}}, \overrightarrow{\mathrm{F}}_{\mathrm{LIFT}, \mathrm{l}}, \overrightarrow{\mathrm{F}}_{\mathrm{TD}, \mathrm{l}}$ are wall lubrication, lift and turbulence dispersion forces, respectively and $\overrightarrow{\mathrm{R}}_{\mathrm{pq}}$ is a interphase drag force. $\quad \mathrm{p}$ is the pressure and the $\bar{\tau}_{\mathrm{q}}$ is the phase stress-strain tensor and computed by Eq.(4);

$$
\bar{\tau}_{1}=\alpha_{1} \mu_{1}\left(\nabla \overrightarrow{\mathrm{u}_{1}}+\nabla \overrightarrow{\mathrm{u}}_{1}^{\mathrm{T}}\right)+\alpha_{1}\left(\lambda_{1}-\frac{2}{3} \mu_{1}\right) \nabla \cdot \overrightarrow{\mathrm{u}_{1}} \overline{\overline{\mathrm{I}}}
$$

Where, $\mu_{1}$ and $\lambda_{1}$ are shear and bulk viscosity, respectively. The interphase drag force in Eq. (3) is defined as;

$$
\overrightarrow{\mathrm{R}}_{\mathrm{vl}}=\sum_{\mathrm{p}=1}^{\mathrm{n}} \mathrm{K}_{\mathrm{vl}}\left(\overrightarrow{\mathrm{u}}_{\mathrm{v}}-\overrightarrow{\mathrm{u}}_{\mathrm{l}}\right)
$$

In which $\mathrm{K}_{\mathrm{vl}}=\mathrm{K}_{\mathrm{lv}}$, is the interphase drag coefficient computed by Eq.(6). In flow boiling, the secondary phase is assumed as dispersed particle in primary phase.

$$
\mathrm{K}_{\mathrm{vl}}=\frac{\alpha_{1} \alpha_{\mathrm{v}} \rho_{\mathrm{v}} \mathrm{f}}{\tau_{\mathrm{p}}}
$$

In Eq. (6), $\tau_{p}$ is the "time relaxation factor" defined as:

$$
\tau_{p}=\frac{\rho_{v} d_{b}^{2}}{18 \mu_{1}}
$$

The drag function $\mathrm{f}$, becomes: 


$$
\mathrm{f}=\frac{\mathrm{C}_{\mathrm{D}} \mathrm{Re}_{\mathrm{b}}}{24}
$$

The value of $C_{D}$ is computed based on the R.Grace model [41] for interphase drag coefficient and this could be obtain by Eq.(9) :

$$
\begin{aligned}
& \mathrm{C}_{\mathrm{D}}=\max \left(\min \left(\mathrm{C}_{\mathrm{D}_{\text {ellipse }}}, \mathrm{C}_{\mathrm{D}_{\text {cap }}}\right), \mathrm{C}_{\mathrm{D}_{\text {sphere }}}\right) \\
& C_{D_{\text {sphere }}}=\left\{\begin{array}{cl}
\frac{24}{\operatorname{Re}} \quad \operatorname{Re}<0.01 \\
\frac{24\left(1+0.15 \mathrm{Re}^{0.687}\right)}{\operatorname{Re}} \quad \mathrm{Re} \geq 0.01
\end{array}\right. \\
& \mathrm{C}_{\mathrm{D}_{\text {cap }}}=\frac{8}{3} \\
& \mathrm{C}_{\mathrm{D}_{\text {ellipse }}}=\frac{4}{3} \frac{\operatorname{gd}_{\mathrm{b}}\left(\rho_{\mathrm{l}}-\rho_{\mathrm{v}}\right)}{\mathrm{U}_{\mathrm{t}}^{2} \rho_{\mathrm{l}}} \\
& \mathrm{U}_{\mathrm{t}}=\frac{\mu_{\mathrm{l}}}{\rho_{\mathrm{l}} \mathrm{d}_{\mathrm{b}}} \mathrm{Mo}^{-0.149}(\mathrm{~J}-0.857) \\
& \text { Mo }=\mu_{1}^{4} \frac{g\left(\rho_{l}-\rho_{\mathrm{v}}\right)}{\rho_{1}^{2} \sigma^{3}} \\
& \mathrm{~J}=\left\{\begin{array}{cc}
0.94 \mathrm{H}^{0.757} & 2<H \leq 59.3 \\
3.42 \mathrm{H}^{0.441} & \mathrm{H}>59.3
\end{array}\right. \\
& \mathrm{H}=\frac{4}{3} \text { Eo Mo }^{-0.149}\left(\frac{\mu_{1}}{\mu_{\text {ref }}}\right)^{-0.14} \\
& \text { Eo }=\frac{g\left(\rho_{l}-\rho_{v}\right) d_{b}}{\sigma} \\
& \mu_{\text {ref }}=0.0009 \mathrm{~kg} \mathrm{~m}^{-1} \mathrm{~s}^{-1}
\end{aligned}
$$

The main advantage of this model is that it takes the deviation shape from spherical shape. The $R e_{b}$ is the bubble Reynolds number based on the relative velocity of phaseswith respect to each other and calculated by Eq.(10) :

$$
\operatorname{Re}_{\mathrm{b}}=\frac{\rho_{\mathrm{l}}\left(\mathrm{u}_{\mathrm{v}}-\mathrm{u}_{\mathrm{l}}\right) \mathrm{d}_{\mathrm{b}}}{\mu_{\mathrm{l}}}
$$

The wall lubrication force impels the produced bubbles to moves from heated wall to the center of pipe. This mechanism plays a very important role in flow boiling by preventing the wall from being covered by vapor. Antal et $a l{ }^{[42]}$ presented an analytical model to predict the value of this force for the first time. This model is used in the present investigation:

$$
\overrightarrow{\mathrm{F}}_{\mathrm{WL}}=\frac{1}{2} \mathrm{C}_{\mathrm{WL}} \rho_{\mathrm{l}} \alpha \mathrm{D}_{\mathrm{S}}\left(\frac{1}{\mathrm{X}^{2}}-\frac{1}{(\mathrm{D}-\mathrm{X})^{2}}\right)\left\|\left(\overrightarrow{\mathrm{u}}_{\mathrm{v}}-\overrightarrow{\mathrm{u}}_{\mathrm{l}}\right) \cdot \overrightarrow{\mathrm{y}}\right\|^{2} \overrightarrow{\mathrm{n}}_{\mathrm{r}}
$$

Where, $\mathrm{X}$ is the distance form wall and $C_{W L}$ coefficient is calculated by Eq. (12)

$$
\begin{gathered}
\mathrm{C}_{\mathrm{WL}}=\max \left(0, \frac{\mathrm{C}_{\mathrm{w} 1}}{\mathrm{~d}_{\mathrm{b}}}+\frac{\mathrm{C}_{\mathrm{w} 2}}{\mathrm{y}_{\mathrm{w}}}\right) \\
\mathrm{C}_{\mathrm{w} 1}=-0.01 ; \mathrm{C}_{\mathrm{w} 2}=0.5 \\
\mathrm{y}_{\mathrm{w}} \leq-\left(\frac{\mathrm{C}_{\mathrm{w} 2}}{\mathrm{C}_{\mathrm{w} 1}}\right) \mathrm{d}_{\mathrm{b}}
\end{gathered}
$$

Lift $^{[43]}$ and turbulence dispersion ${ }^{[44]}$ forces, are defined as follows:

$$
\begin{gathered}
\overrightarrow{\mathrm{F}}_{\mathrm{LIFT}, \mathrm{l}}=\mathrm{C}_{\mathrm{l}} \alpha_{\mathrm{v}} \rho_{\mathrm{l}}\left(\overrightarrow{\mathrm{u}_{\mathrm{v}}}-\overrightarrow{\mathrm{u}_{\mathrm{l}}}\right) \times\left(\nabla \times \overrightarrow{\mathrm{u}_{\mathrm{l}}}\right) \\
\overrightarrow{\mathrm{F}}_{\mathrm{TD}, \mathrm{l}}=-\mathrm{C}_{\mathrm{TD}} \rho_{\mathrm{l}} \mathrm{\kappa} \nabla \alpha_{\mathrm{v}}
\end{gathered}
$$

In Eq. (13),$C_{l}$ is lift coefficient and computed by Eq. $(15)^{[43]}$ :

$$
C_{l}=\left\{\begin{array}{lr}
0.00767 & \text { if } \psi \leq 6 \times 10^{3} \\
\left(0.12-0.2 \mathrm{e}^{\frac{-\psi}{3.6 \times 10^{5}}}\right) \mathrm{e}^{\frac{\psi}{3 \times 10^{7}}} & \text { if } 6 \times 10^{3}<\psi<1.9 \times 10^{5} \\
-0.002 & \text { if } \psi \geq 1.9 \times 10^{5}
\end{array}\right.
$$

Where $\psi=R e_{b} R e_{\nabla}$ that $R e_{b}$ is bubble Reynolds number which calculated by Eq.(10) and $R e_{\nabla}$ is shear Reynolds number obtained by Eq. (16) :

$$
\operatorname{Re}_{\nabla}=\frac{\rho_{\mathrm{l}} \mathrm{d}_{\mathrm{b}}^{2}}{\mu_{\mathrm{l}}}\left(\nabla \cdot \overrightarrow{\mathrm{u}_{\mathrm{l}}}\right)
$$


In Eq. (14), $\kappa$ is the turbulence kinetic energy and $C_{T D}=1^{[44]}$

At the above equations (Eqs.(7,9,10,12 and 16)), $d_{b}$ is the bubble diameter of vapor phase and obtained by a function suggested by Kurul and Podowski[45] as follows :

$$
\mathrm{d}_{\mathrm{b}}=\left\{\begin{array}{lr}
0.0015 & \Delta \mathrm{T}_{\text {sub }}<0 \\
0.00015-0.0001 \Delta \mathrm{T}_{\text {sat }} & 0<\Delta \mathrm{T}_{\text {sub }}<13.5 \\
0.00015 & \Delta \mathrm{T}_{\text {sub }}>13.5
\end{array}\right.
$$

\subsection{Turbulence model}

For considering the turbulence of two-phase flows, the usual formulations of turbulence quantities for single phase flow are used modified by adding some terms accounting for the turbulence induced by the presence of the other phase. According to the literature, and specially the study of Zhang et.al ${ }^{[25]}$, the $\mathrm{k}-\varepsilon$ realizable turbulence model is used in this study. In modeling subcooled flows, the turbulent equations only for liquid phase by adding terms for bubble-induced turbulence, and determine the effect of turbulence on the vapor bubbles by introducing a force in the momentum equations. The logarithmic wall function is used in here for wall boundary condition with appropriate $y^{+}$value above 11.23 .

\subsection{Energy equation}

The energy equation for each phases in the model is described as follows;

$$
\begin{aligned}
\frac{\partial}{\partial \mathrm{t}}\left(\alpha_{\mathrm{l}} \rho_{\mathrm{l}} \mathrm{h}_{\mathrm{l}}\right)+ & \nabla \cdot\left(\alpha_{\mathrm{l}} \rho_{\mathrm{l}} \overrightarrow{\mathrm{u}}_{\mathrm{l}} \mathrm{h}_{\mathrm{l}}\right)=\alpha_{\mathrm{l}} \frac{\partial \mathrm{p}_{\mathrm{l}}}{\partial \mathrm{t}}+\overrightarrow{\mathrm{\tau}}_{\mathrm{l}}: \nabla \overrightarrow{\mathrm{u}}_{\mathrm{l}}-\nabla \cdot \overrightarrow{\mathrm{q}}_{\mathrm{l}}+ \\
& +\sum_{\mathrm{v}=1}^{\mathrm{n}}\left(\mathrm{Q}_{\mathrm{vl}}+\dot{\mathrm{m}}_{\mathrm{vl}} \mathrm{i}_{\mathrm{vl}}-\dot{\mathrm{m}}_{\mathrm{lv}} \mathrm{i}_{\mathrm{l}}\right)
\end{aligned}
$$

Where, $h_{l}, \vec{q}_{l}$ and $Q_{v l}$ is phase enthalpy, heat flux within the 1 phase, and the rate of heat transfer between two phases, respectively. $i_{v l}$ represents the interphase enthalpy due to phase change, which here becomes enthalpy of vaporization. The interphase heat transfer is defined as;

$$
\mathrm{Q}_{\mathrm{vl}}=\mathrm{h}_{\mathrm{vl}}\left(\mathrm{T}_{\mathrm{v}}-\mathrm{T}_{\mathrm{l}}\right)
$$

The values of $h_{v l}$ and $h_{l v}$ are equal and presented by Eq.(20);

$$
\mathrm{h}_{\mathrm{vl}}=\frac{6 \kappa_{\mathrm{l}} \alpha_{\mathrm{v}} \alpha_{\mathrm{l}} \mathrm{Nu}_{\mathrm{v}}}{\mathrm{d}_{\mathrm{b}}^{2}}
$$

$\kappa_{l}$ is the liquid phase thermal conductivity. The interphase heat transfer coefficient is calculated by RanzMarshal ${ }^{[46]}$ Nusselt number $N u_{v}$;

$$
\mathrm{Nu}_{\mathrm{v}}=2.0+0.6 \operatorname{Re}_{\mathrm{b}}^{1 / 2} \operatorname{Pr}^{1 / 3}
$$

In Eq.(21), $R e_{b}$ is the relative Reynolds number (Eq.(10)) based on bubble diameter and relative velocity between two phases. The Prandel number is calculated as follows;

\subsection{Boiling model}

$$
\operatorname{Pr}=\frac{c_{p_{1}} \mu_{1}}{\kappa_{1}}
$$

For phase change description, the Bulk boiling model based on the Lee ${ }^{[47]}$ was used. In this model, mass transfer is modeled as follows:

$$
\begin{gathered}
\left\{\begin{array}{cc}
\dot{\mathrm{m}}_{\mathrm{lv}}=\mathrm{r}_{\mathrm{l}} \alpha_{\mathrm{l}} \rho_{\mathrm{l}} \frac{\left(\mathrm{T}_{\mathrm{l}}-\mathrm{T}_{\mathrm{sat}}\right)}{\mathrm{T}_{\mathrm{sat}}} \mathrm{T}_{\mathrm{l}} \geq \mathrm{T}_{\mathrm{sat}} \\
0 & \mathrm{~T}_{\mathrm{l}}<\mathrm{T}_{\mathrm{sat}}
\end{array}\right. \\
\left\{\begin{array}{cc}
\dot{\mathrm{m}}_{\mathrm{vl}}=\mathrm{r}_{\mathrm{v}} \alpha_{\mathrm{v}} \rho_{\mathrm{v}} \frac{\left(\mathrm{T}_{\mathrm{sat}}-\mathrm{T}_{\mathrm{v}}\right)}{\mathrm{T}_{\mathrm{sat}}} \mathrm{T}_{\mathrm{v}} \leq \mathrm{T}_{\mathrm{sat}} \\
0 & \mathrm{~T}_{\mathrm{v}}>\mathrm{T}_{\text {sat }}
\end{array}\right.
\end{gathered}
$$

Where $r_{l}$ and $r_{v}$ are mass transfer time parameters. In this study $r_{l}$ and $r_{v}$ are set to be $0.1 s^{-1}$.

\section{Numerical method}

The aforementioned set of equations are solved together using finite volume based solver FLUENT code. In order to create pressure-velocity coupling, the phase coupled SIMPLE algorithm was used. For discretization diffusion and convection terms, second-order of central and upwind scheme was used, respectively. The time step was typically $10^{-5} s$ for two-phase flow boiling simulation. For validation of the presented model, four different experimental 
pressure drops in flow boiling in small helically coiled tube conducted by Cioncolini et.al[40] were numerically simulated. The experimental conditions are presented in Table 1 for four simulated tests. The exit vapor quality for each experimental case is calculated using thermodynamic calculations. Thermo-physical properties of water and vapor are assumed based on the temperature.

\begin{tabular}{|l|l|l|l|l|l|l|}
\hline Case & $\mathbf{P}(\mathbf{K p a})$ & $\mathbf{G}\left(\mathbf{k g} / \mathbf{m}^{2} \mathbf{s}\right)$ & $\mathbf{q}\left(\mathbf{k w} / \mathbf{m}^{2}\right)$ & $\Delta \mathbf{T}_{\text {sub }}\left({ }^{\circ} \mathbf{C}\right)$ & \multicolumn{1}{|c|}{$\mathbf{L}_{\text {sub }}(\mathbf{m})$} & $\mathbf{x}_{\text {exit }}(\mathbf{\%})$ \\
\hline 1 & 286 & 489 & 163 & 29.1 & 0.45 & 4.83 \\
\hline 2 & 286 & 332 & 224 & 55.6 & 0.42 & 10.38 \\
\hline 3 & 467 & 414 & 330 & 40.4 & 0.26 & 17.58 \\
\hline 4 & 459 & 397 & 369 & 55 & 0.30 & 18.93 \\
\hline
\end{tabular}

Table1. The four different experimental cases for comparing with numerical code based on the Cioncolini et.al ${ }^{[40]}$

The four experimental tests are selected in a way to cover low vapor quality region of experiments performed by Cioncolini et. $a{ }^{[40]}$. In order to grid independence test and verify the numerical method, the obtained results for pressure drop by simulations were compared to those of the experiments. As it is shown in Figure 3, the results show satisfactory agreement with the reported pressure drops in literature ${ }^{[40]}$.

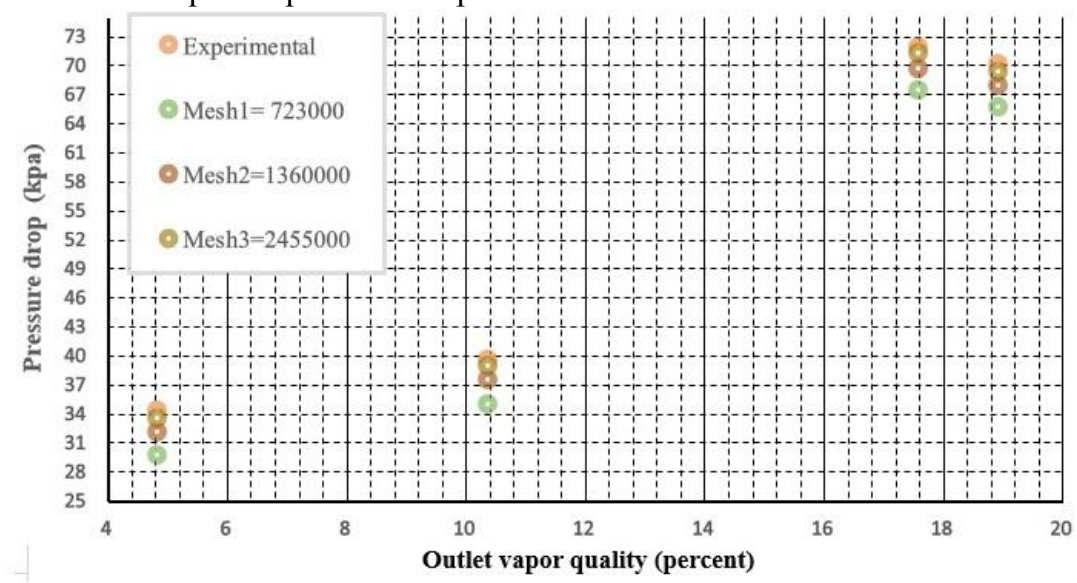

Figure 3; Grid independency test and verify the numerical method by by Cioncolini et.al experimental tests ${ }^{[0]}$

Therefore, the final mesh as shown in Figure 4 is used in the present study in order to investigate the flow boiling in helically coiled tube.

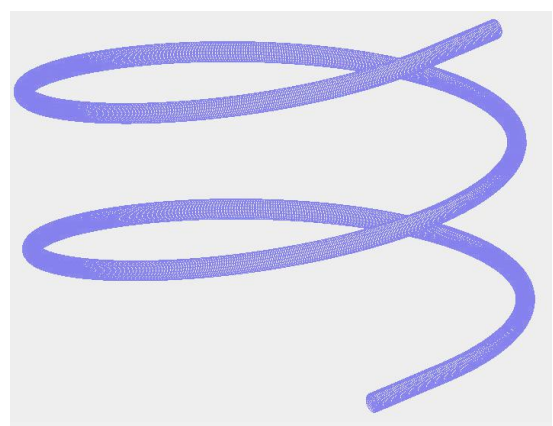

(a)

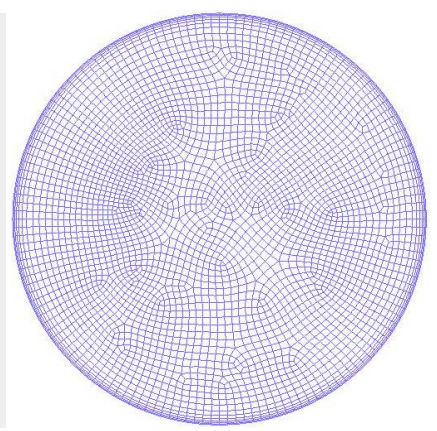

(b)

Figure 4; (a) The mesh of the helically coiled tube (b) the cross section of mesh.

\section{Results and discussion:}

\subsection{The variation of vapor volume fraction along the coiled tube}

The results for first case in Table $\mathbf{1}$ are discussed here with more details. The exit vapor quality in this test is 4.83 percent and the liquid subcooling is $29.1 \mathrm{~K}$. The contours for vapor volume fraction distribution at different positions along the helically coiled tube are shown in Figure 5. As it shows, at the beginning of boiling, the effect of gravity and centrifugal force shows some vapor at $\varphi=270^{\circ}$. The asymmetric shape in generated vapor is due to the radial pressure 
gradient of the helically coiled tube. This effect is more obvious at $\varphi=450^{\circ}$ as shown in this figure.

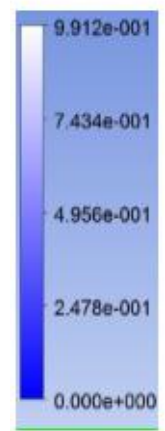

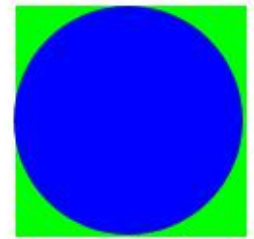

$\varphi=180^{\circ}$

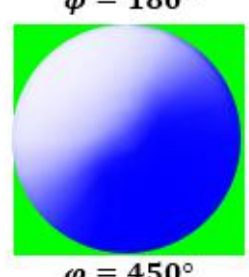

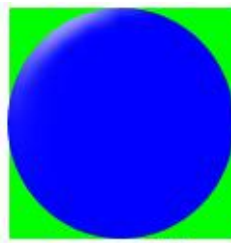

$\varphi=270^{\circ}$

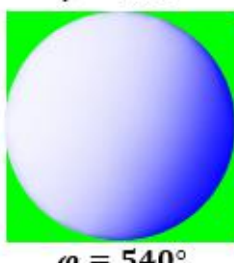

$\varphi=540^{\circ}$

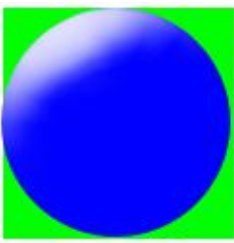

$\varphi=360^{\circ}$

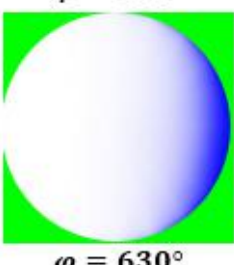

Figure 5; Vapor volume fraction in the helically coiled tube at different helical angles for the first case in Table 1.

\subsection{The variation of void fraction along the coiled tube}

The variation of the void fraction with vapor quality is shown in Figure 6 for first case in Table 1. The value of the vapor quality is computed as follows;

$$
\mathrm{x}=\frac{\mathrm{i}-\mathrm{i}_{1}}{\mathrm{i}_{\mathrm{lv}}}
$$

In Eq. (24), $\mathrm{i}$ is the liquid enthalpy which is calculated based on the heat transferred to the fluid in each cross section.

$$
\mathrm{i}=\frac{\dot{\mathrm{Q}}}{\dot{\mathrm{m}}}-\mathrm{i}_{\text {in }}
$$

Where, $\dot{Q}$ is the heat transfer to the fluid to the assumed cross section, $\dot{m}$ is the mass flow rate, and $i_{\text {in }}$ is the inlet fluid enthalpy. The negative value of the vapor quality at first part of the tube is determined the subcooling of the fluid. Figure 6 shows that the increasing in the value of wall temperature to the saturated one, the process of boiling starts with very low vapor volume fraction and liquid subcooling. In downstream, the increase in the temperature of the fluid bulk causes the bubbles are united with each other and generating bubbles near the wall dramatically increases. This process leads to increase the value of vapor volume fraction even at zero vapor quality when the saturated boiling starts as shown in Figure 6.

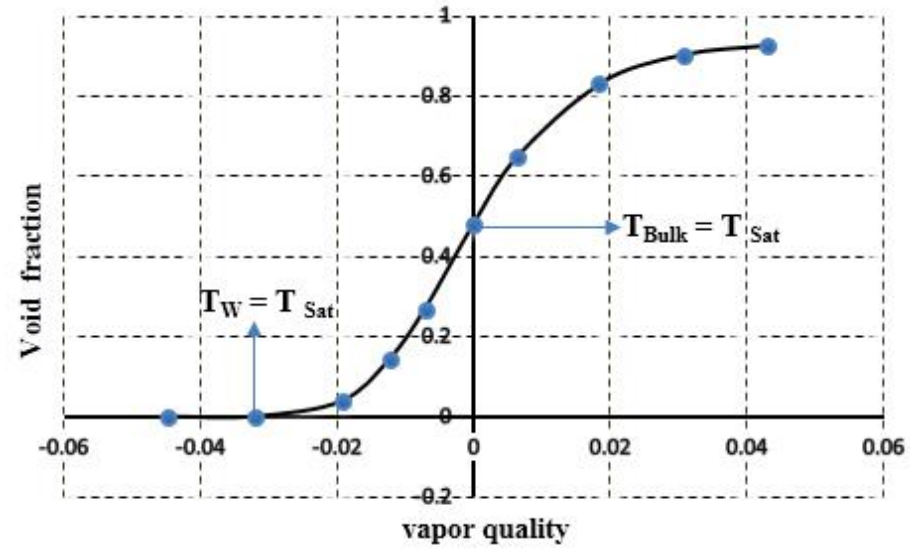

Figure 6; The variation of the void fraction versus the vapor quality for the first case in Table 1.

heat transfer coefficient in different peripheral angles along the helically coiled tube

The centrifugal and gravity forces make the different wall temperatures and heat transfer coefficient in different peripheral angles of the coil. These angles in one cross section are shown in Figure 7. 


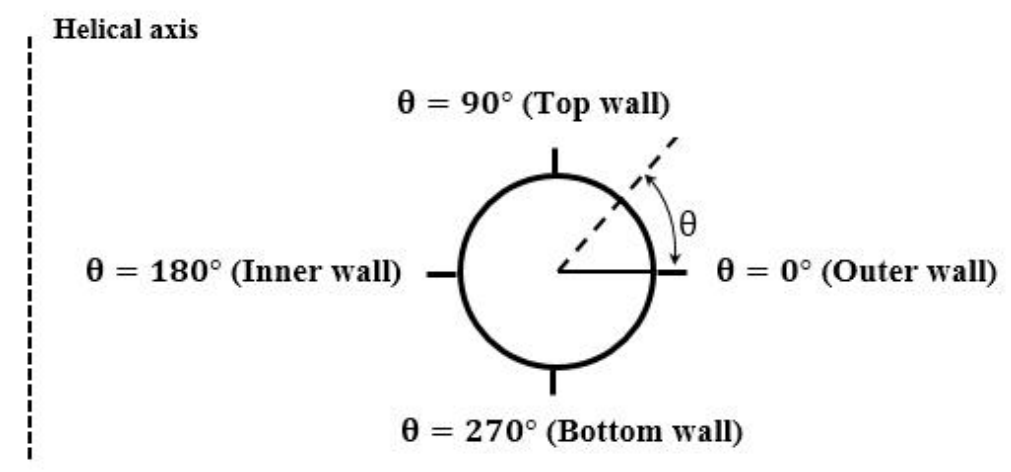

Figure 7; The peripheral angle of one arbitrary cross section of the helically coiled tube.

Figure 8 shows the variation of the heat transfer coefficient at different peripheral angles of the helically coiled tube along its length. As shown in this figure, the gravity and centrifugal forces cause the accumulating of the vapor on the inner wall $\left(\theta=180^{\circ}\right)$ and the top of the the coil $\left(\theta=90^{\circ}\right)$ (Figure 5) which leads to decrease heat transfer coefficient. For the outer wall $\left(\theta=0^{\circ}\right)$, the heat transfer coefficient is more than other peripheral portions due to accumulating the liquid at there. (see Figure 5).

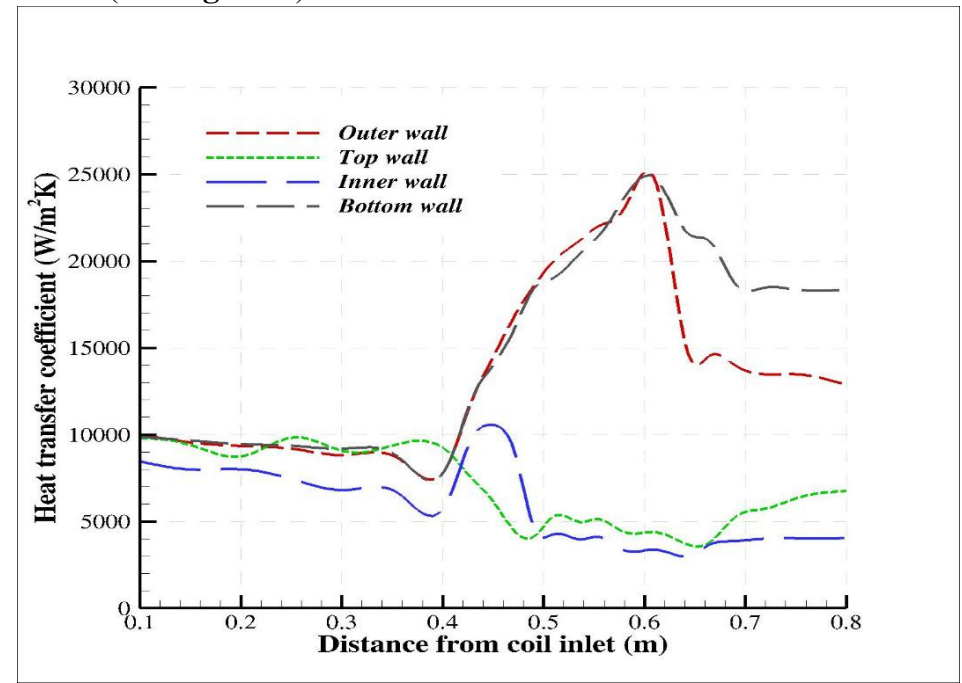

Figure 8; The peripheral heat transfer coefficient along the helically coiled tube for the first case in Table 1.

\subsection{The effect of coil diameter on vapor volume fraction}

In order to study the effect of coil diameter on vapor volume fraction, two coils studied and compared with each other for the forth case in Table 1. The coil diameters are assumed to be $130 \mathrm{~mm}$ and $260 \mathrm{~mm}$. It must be mentioned that, the tube diameter and helical pitch is $4.98 \mathrm{~mm}$ and $40.3 \mathrm{~mm}$, respectively. In order to compare the effect of coil diameter on the vapor volume fraction, the same length $\left(L_{s}\right)$ from entrance of coil tube must be defined. In Figure 9, the vapor volume fraction of two coil diameters are compared at the same length with each other. This figure shows that, the increase in the coil diameter causes the intensity of the radial pressure gradient decreases. The reduction in the radial pressure gradient leads to more vapor coverage in the cross section of the tube as shown in Figure 9 (b). 


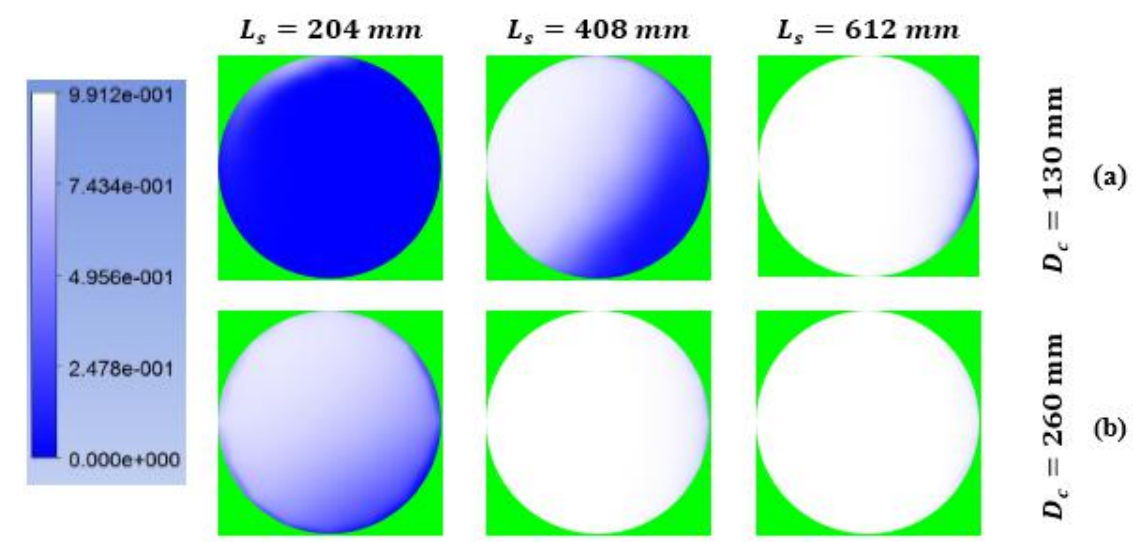

Figure 9; The effect of coil diameter on the vapor volume fraction distribution (a) $D_{c}=130 \mathrm{~mm}$ (b) $D_{c}=260 \mathrm{~mm}$ for the forth case in Table 1.

\subsection{Effect of coil diameter on heat transfer coefficient on the inner and outer walls}

The trend of change in the heat transfer coefficient on the inner wall, for three different coil diameters of $130 \mathrm{~mm}$, $260 \mathrm{~mm}$ and $390 \mathrm{~mm}$ for forth case in Table 1 is presented in Figure 10. The reduction in the coil diameter cause the intensity of the radial pressure gradient increases leads to the increase in wall lubrication effect which forces more bubbles leaving the inner wall. Therefore, on boiling onset as the process of generation of bubbles and leaving from the inner wall increases, the heat transfer coefficient increases along the coil and is higher for smaller coils at low vapor quality region. Increase in the value of heat transfer coefficient is not stable due to the accumulating of vapor on the inner wall. Therefore, the value of heat transfer coefficient approaches to the single phase heat transfer coefficient. As shown in Figure $\mathbf{1 0}$ at downstream where the value of vapor quality along the helical coil pipe increases, the contribution of vapor increases with respect to liquid on inner wall (because of radial pressure gradient effect) which leads to the reduction in heat transfer coefficient. Accumulating of vapor on the inner wall is more intense in small coils tube which makes lower heat transfer coefficients for small helically coiled tube in comparison to larger ones.

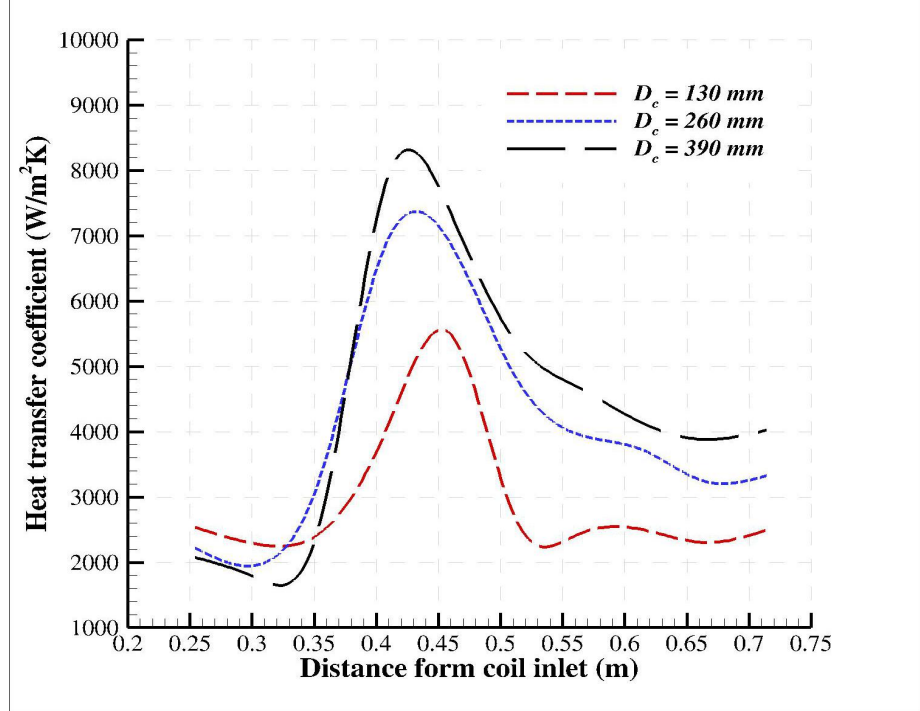

Figure 10; The effect of coil diameter on the heat transfer coefficient on the inner wall for the forth case in Table 1.

On the outer wall, as indicated in Figure 11, the liquid film shows a better heat transfer coefficient for small coil due to the radial pressure gradient which still stands liquid even in the higher vapor quality. As the radial pressure increases by reduction in the coil diameter, this behavior is more obvious. Therefore small coils have better heat transfer coefficient on outer wall at both low and high vapor quality regions. 


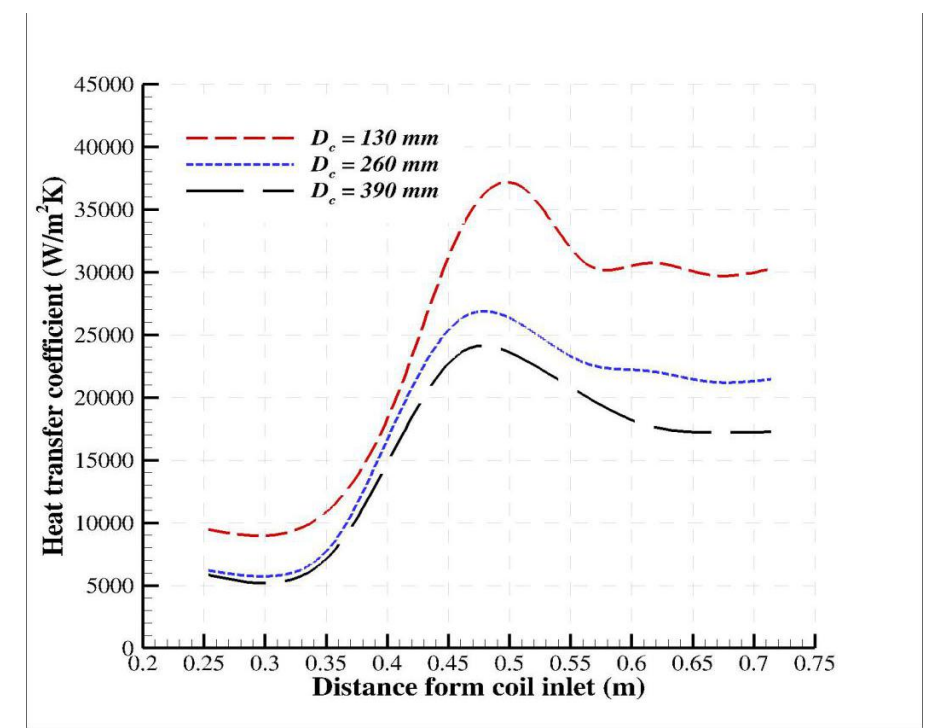

Figure 11; The effect of coil diameter on the heat transfer coefficient for liquid film (on the outer wall) for the forth case in Table 1.

\subsection{Effect of the helical pitch on vapor volume fraction of coiled tube}

The effect of the helical pitch on vapor volume fraction is presented in Figure 12 for two helical pitch of $27 \mathrm{~mm}$, and $60.6 \mathrm{~mm}$ for helically coiled tube for the fourth case in Table $\mathbf{1}$. The tube and coil diameters are $4.98 \mathrm{~mm}$ and 130 $\mathrm{mm}$, respectively. This figure shows at constant same length, as the helically pitch increases, the dried region slightly reduces. By increasing helical pitch, effect of buoyancy (due to the gravity) on vapor bubbles increase cause better lift off for bubbles from the heating surface and it makes more wet region.

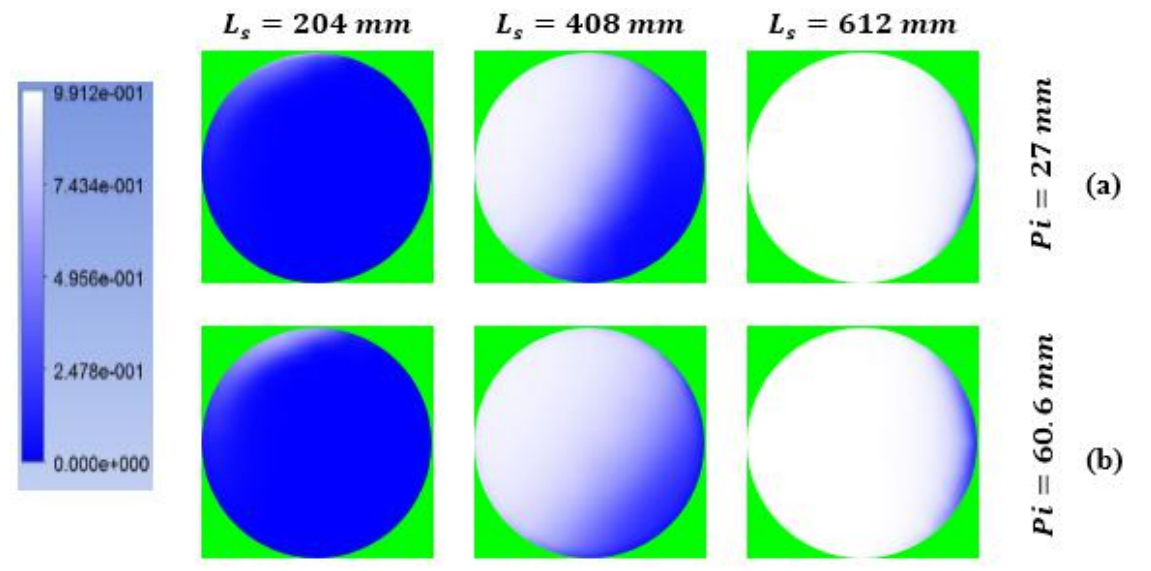

Figure 12; The effect of the coil pitch on the vapor volume fraction distribution (a) $\mathrm{Pi}=27 \mathrm{~mm}$ (b) $\mathrm{Pi}=60.6 \mathrm{~mm}$ for the fourth case in Table 1.

\subsection{Effect of the helical pitch on heat transfer coefficient of the coiled tube}

The effect of three different helical pitches $(27 \mathrm{~mm}, 40.3 \mathrm{~mm}$ and $60.6 \mathrm{~mm})$ on heat transfer coefficient at the inner and outer walls show in Figure 13 and Figure 14. 


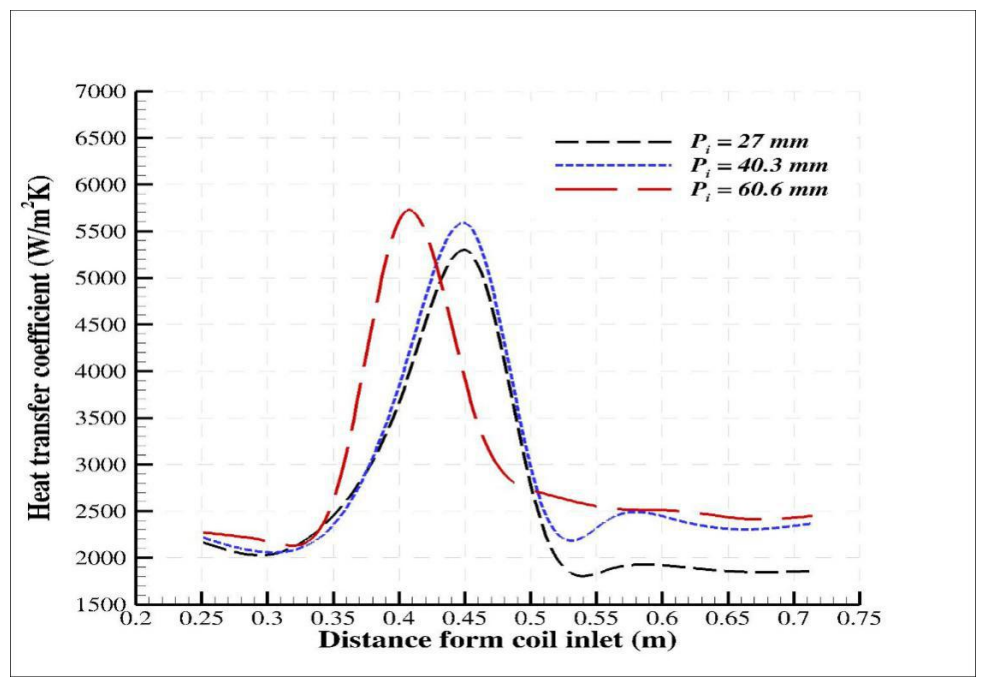

Figure 13; The effect of helical pitch on the heat transfer coefficient on the inner wall for the fourth case in Table 1.

At the earlier region of the coils, the domination of the boiling cause the three coil have the same behavior. By getting away from the entrance of coiled tube, the fluid in coils with bigger pitches experiences a greater buoyancy (due to the gravity) which leads to the better moving of the vapor bubbles to the exit of the helically coiled tube. The better vapor moving through the exit of the tube avoid accumulating of the bubbles near the wall and result in the higher heat transfer coefficient. In fact, the increase in the helical pitch cause the geometry of the helically coiled tube approaches to the straight vertical tube. As mentioned by Kandlikar ${ }^{[48]}$, the heat transfer coefficient in the vertical straight tube is more than the straight horizontal one.

\subsection{Effect of the tube diameter on vapor volume fraction of coiled tube}

Investigation of effect of tube diameter on vapor volume fraction is presented in Figure $\mathbf{1 5}$ for two tube diameters of $4.98 \mathrm{~mm}$ and $10 \mathrm{~mm}$ for helically coiled tube for the fourth case in Table 1 . The coil pitch and coil diameter are 40.3 $\mathrm{mm}$ and $130 \mathrm{~mm}$, respectively. This figure indicates that as the tube diameter increases, the dried region slightly increases. Increase in tube diameter leads to increase in mass flow rate and heat transfer surface. This phenomenon cause the generation of more bubbles, especially on the top and inner walls.

\subsection{Effect of the tube diameter on total heat transfer coefficient of coiled tube}

The effect of two different tube diameters $(4.98 \mathrm{~mm}$ and $10 \mathrm{~mm})$ of helically coiled tube with same coil pitch of $40.3 \mathrm{~mm}$ and coil diameter of $130 \mathrm{~mm}$, on total heat transfer coefficient was shown in Figure 16. The reduction in tube diameter cause the thickness of boundary layer decreases, leads to decrease in heat resistance between wall and fluid. Therefore, the value of heat transfer coefficient increases. The boundary layer creation cause the heat transfer coefficient decreases up to 0.3 meter form inlet of coil. Due to bubble generation, the heat transfer coefficient increases. Accumulating bubble near wall causes heat transfer coefficient reduces again. 


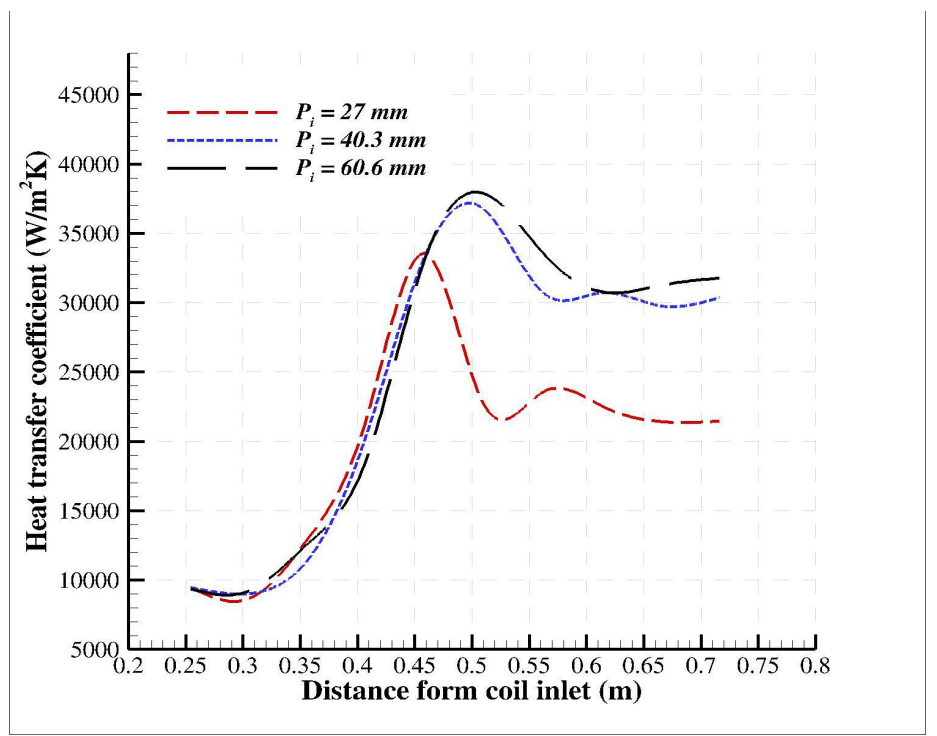

Figure 14; The effect of helical pitch on the heat transfer coefficient for the liquid film (on the outer wall) for the fourth case in Table 1.

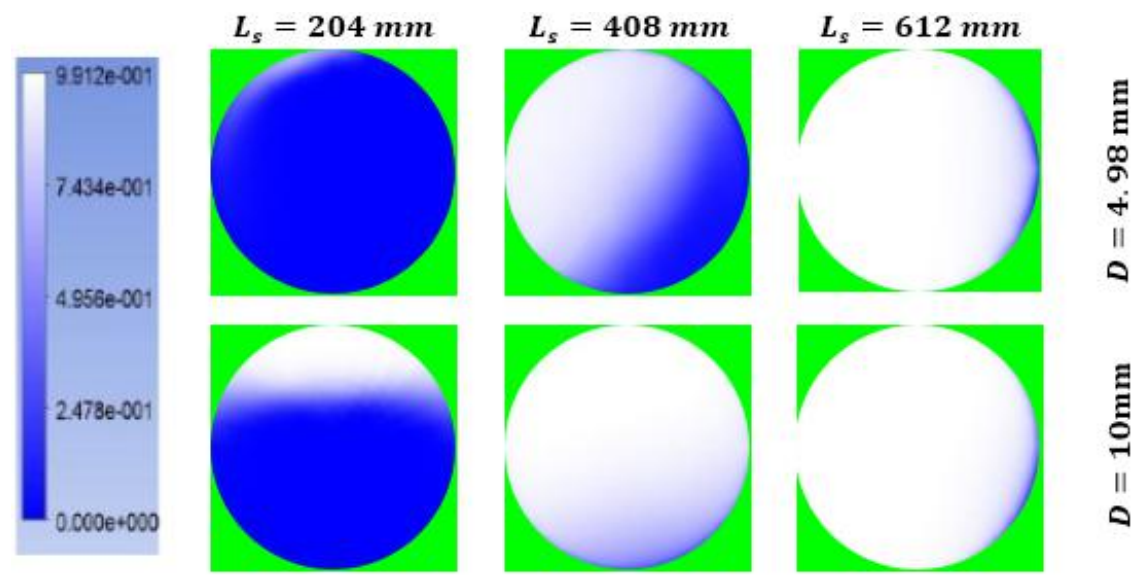

Figure 15; The effect of the tube diameter on vapor volume fraction distribution (a) $\mathrm{D}=4.98 \mathrm{~mm}$ (b) $\mathrm{D}=10 \mathrm{~mm}$ for the fourth case in Table 1.

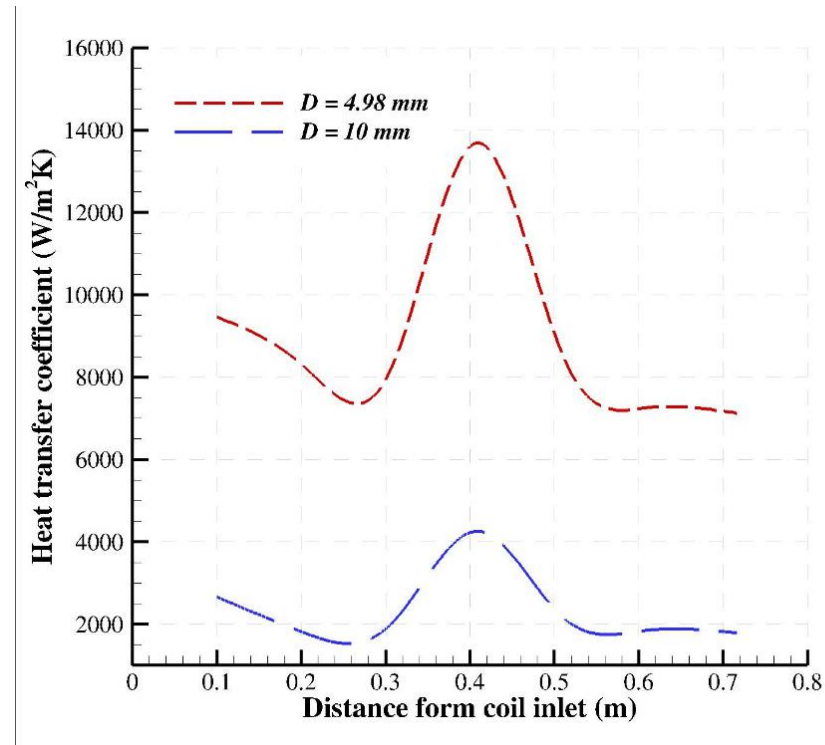

Figure 16; The effect of tube diameter on the total heat transfer coefficient for the fourth case in Table 1. 


\section{Conclusion}

Flow boiling in the helically coiled tube is simulated at low vapor quality region (up to the 18.93 percent) in this paper. The proper mathematical model must be used in order to analyze boiling process in presence of the radial pressure gradient and gravity forces. Comparison of numerical method and experimental results shows a good agreement. The radial pressure gradient cause accumulating of more vapor bubble on the inner wall with respect to the outer one of coiled tube. Generally, heat transfer coefficient is better on the outer wall in comparison with inner one. The increase in helical pitch creates more wet region on heating surface and increase the heat transfer coefficient on both of inner and outer wall. The increase in the coil diameter leads to emerge more vapor coverage in the cross section of the tube. The reduction in the coil diameter, make higher heat transfer coefficient at low vapor quality region and low heat transfer coefficient at high vapor quality region on inner wall. For outer wall, small coils have better heat transfer coefficients at both of low and high vapor quality regions. Increasing tube diameter leads to more vapor generating and accumulation whereas small tube diameter leads to better heat transfer coefficient.

\section{List of symbols}

$\mathrm{d}_{\mathrm{b}}$

bubble diameter (m)

$D_{c}$

coil diameter

D

tube diameter

force $(\mathrm{N})$

G

mass velocity $\left(\mathrm{kgm}^{2} \mathrm{~s}^{-1}\right)$

Greek symbols

$\begin{array}{ll}\alpha & \begin{array}{l}\text { volume fraction } \\ \text { density }\left(\mathrm{kgm}^{-3}\right)\end{array} \\ \mu & \text { dynamic viscosity (Pa.s) } \\ \varphi & \text { helically coil angle (deg.) } \\ \theta & \text { peripheral angle (deg.) }\end{array}$




$\begin{array}{ll}\text { Subscripts } & \\ \mathrm{b} & \text { bubble } \\ \mathrm{I} & \text { liquid phase } \\ \mathrm{v} & \text { vapor phase } \\ \text { WL } & \text { wall lubrication } \\ \text { TD } & \text { turbulence dispersion }\end{array}$

\section{References}

1. Vashisth S, Nigam KDP (2009) Prediction of flow profiles and interfacial phenomena for two-phase flow in coiled tubes. Chem Eng Process Process Intensif 48:452-463. doi: 10.1016/j.cep.2008.06.006

2. Xia GD, Liu XF, Zhai YL, Cui ZZ (2014) Single-phase and two-phase flows through helical rectangular channels in single screw expander prototype. J Hydrodyn 26:114-121. doi: 10.1016/S1001-6058(14)60013-5

3. Durst F, Germany W (1984) Eulerian and Lagrangian predictions of particulate two- phase flows : a numerical study. Appl Math Model 8:101-115.

4. Gouesbet G, Berlemont a. (1998) Eulerian and Lagrangian approaches for predicting the behaviour of discrete particles in turbulent flows. Prog Energy Combust Sci 25:133-159. doi: 10.1016/S0360-1285(98)00018-5

5. Zhang Z, Chen Q (2007) Comparison of the Eulerian and Lagrangian methods for predicting particle transport in enclosed spaces. Atmos Environ 41:5236-5248. doi: 10.1016/j.atmosenv.2006.05.086

6. Kurul N, Podowski MZ (1990) Multidimensional effects in forced convection subcooled boiling. In: Proc. Ninth Int. Heat Transf. Conf. Jerusalem, Israel, pp 21-26

7. Končar B, Kljenak I, Mavko B (2004) Modelling of local two-phase flow parameters in upward subcooled flow boiling at low pressure. Int J Heat Mass Transf 47:1499-1513. doi: 10.1016/j.ijheatmasstransfer.2003.09.021

8. Bartel M. (1999) Experimental investigation of subcooled boiling. Master Thesis, Purdue University, West Lafayette, Indiana, USA

9. Li X, Wang R, Huang R, Shi Y (2006) Numerical investigation of boiling flow of nitrogen in a vertical tube using the two-fluid model. Appl Therm Eng 26:2425-2432.

10. Chen E, Li Y, Cheng X (2009) CFD simulation of upward subcooled boiling flow of refrigerant-113 using the two-fluid model. Appl Therm Eng 29:2508-2517. doi: 10.1016/j.applthermaleng.2008.12.022

11. Kang S, Roy RP (2002) Vapor Phase Measurements in Subcooled Boiling Flow. J Heat Transfer 124:1207. doi: $10.1115 / 1.1517269$

12. Roy RP, Kang S, Zarate J a., Laporta a. (2002) Turbulent Subcooled Boiling Flow—Experiments and Simulations. J Heat Transfer 124:73. doi: 10.1115/1.1418698

13. Končar B, Krepper E (2008) CFD simulation of convective flow boiling of refrigerant in a vertical annulus. Nucl Eng Des 238:693-706. doi: 10.1016/j.nucengdes.2007.02.035

14. Abishek S, King AJC, Narayanaswamy R (2017) Computational analysis of two-phase flow and heat transfer in parallel and counter flow double-pipe evaporators. Int J Heat Mass Transf 104:615-626. doi: 10.1016/j.ijheatmasstransfer.2016.08.089

15. Zeitoun O, Shoukri M (1997) Axial void fraction profile in low pressure subcooled flow boiling. Int J Heat Mass Transf 40:869-879. doi: 10.1016/0017-9310(96)00164-0

16. Kommer E. (2013) Forced Convective Boiling Via Infrared Thermography. Ph.D. Thesis, The University of Maryland, USA

17. Sun DL, Xu JL, Wang L (2012) Development of a vapor-liquid phase change model for volume-of-fluid method in FLUENT. Int Commun Heat Mass Transf 39:1101-1106. doi: 10.1016/j.icheatmasstransfer.2012.07.020

18. Sun D, Xu J, Chen Q (2014) Modeling of the Evaporation and Condensation Phase-Change Problems with FLUENT. Numer Heat Transf Part B Fundam 66:326-342. doi: 10.1080/10407790.2014.915681

19. Welch SWJ, Wilson J (2000) A Volume of Fluid Based Method for Fluid Flows with Phase Change. J Comput Phys 160:662-682. doi: 10.1006/jcph.2000.6481

20. Guo DZ, Sun DL, Li ZY, Tao WQ (2011) Phase Change Heat Transfer Simulation for Boiling Bubbles Arising from a Vapor Film by the VOSET Method. Numer Heat Transf Part A Appl 59:857-881. doi: $10.1080 / 10407782.2011 .561079$

21. Son G, Dhir VK (1998) Numerical Simulation of Film Boiling Near Critical Pressures With a Level Set Method. J Heat Transfer 120:183-192. doi: 10.1115/1.2830042

22. Klimenko V V. (1981) Film boiling on a horizontal plate - new correlation. Int J Heat Mass Transf 24:69-79. doi: 
10.1016/0017-9310(81)90094-6

23. Nichita B, Thome J (2010) A level set method and a heat transfer model implemented into FLUENT for modeling of microscale two phase flows. ... 178 Spec Meet Syst Lev ... 1-15.

24. Mao W. (2009) Numerical Simulation of Vapor-liquid Phase Change Heat Transfer and Micromixing in Microfluidic Systems. Master's thesis, Guangzhou Institute of Energy Conversion Chinese Academy of Sciences, China

25. Zhang R, Cong T, Tian W, et al (2015) Effects of turbulence models on forced convection subcooled boiling in vertical pipe. Ann Nucl Energy 80:293-302. doi: 10.1016/j.anucene.2015.01.039

26. Bartolemei G., Chanturiya V. (1967) Experimental study of true void fraction when boiling subcooled water in vertical tubes. Therm Eng 14:123-128.

27. Bartolemei G., Brantov V., Molochnikov Y., et al (1982) An experimental investigation of true volumetric vapor content with subcooled boiling in tubes. Therm Eng 29:132-135.

28. Yang Z, Peng XF, Ye P (2008) Numerical and experimental investigation of two phase flow during boiling in a coiled tube. Int J Heat Mass Transf. doi: 10.1016/j.ijheatmasstransfer.2007.05.025

29. Nadim N (2012) Fluid and thermal behavior of multi-phase flow through curved ducts. PhD Thesis, Curtin University, School of Civil and Mechanical Engineering, Department of Mechanical Engineering, Bentley, Perth, Western Australia

30. St. Pierre CC, Bankoff SG (1967) Vapor Volume Profiles in Developing Two-Phase Flow. Int J Heat Mass Transf 10:237-249.

31. Wu HL, Peng XF, Ye P, Eric Gong Y (2007) Simulation of refrigerant flow boiling in serpentine tubes. Int J Heat Mass Transf 50:1186-1195. doi: 10.1016/j.ijheatmasstransfer.2006.10.013

32. Aminfar H, Mohammadporfard M, Maroofiazar R (2013) Eulerian simulation of subcooled boiling flow in straight and curved annuli. J Mech Sci Technol. doi: 10.1007/s12206-013-0501-4

33. Lee TH, Park GC, Lee DJ (2002) Local flow characteristics of subcooled boiling flow of water in a vertical concentric annulus. Int J Multiph Flow 28:1351-1368.

34. Jo JC, Kim WS, Choi C-Y, Lee YK (2009) Numerical Simulation of Subcooled Flow Boiling Heat Transfer in Helical Tubes. J Press Vessel Technol 131:011305. doi: 10.1115/1.3028022

35. Owhadi A (1968) Forced convection boiling inside helically-coiled tubes. Int J Hear Mass Transf 11:1779-1793.

36. Colorado D, Papini D, Hernández J a., et al (2011) Development and experimental validation of a computational model for a helically coiled steam generator. Int J Therm Sci 50:569-580. doi: 10.1016/j.ijthermalsci.2010.10.018

37. Colorado-Garrido D, Santoyo-Castelazo E, Hernández JA, et al (2009) Heat transfer of a helical double-pipe vertical evaporator: Theoretical analysis and experimental validation. Appl Energy 86:1144-1153. doi: 10.1016/j.apenergy.2008.08.015

38. Santini L Thermalhydraulic issues of IRIS nuclear reactor helicallyly coiled steam generator and emergency heat removal system. Ph.D Thesis, Dipartimento di Ingegneria Nucleare, Politecnico di Milano, Milan, Italy

39. Santoyo-Castelazo E, Siqueiros J (2007) Estudio experimental de un sistema de purificacin de agua integrado a un transformador térmico. Memorias del. In: XXVIII Encuentro Nac. la AMIDIQ. Mexico, pp 4072-4085

40. Cioncolini A, Santini L, Ricotti ME (2008) Subcooled and saturated water flow boiling pressure drop in small diameter helical coils at low pressure. Exp Therm Fluid Sci 32:1301-1312. doi: 10.1016/j.expthermflusci.2008.03.002

41. Clift R, Grace R, Weber M. (1978) Bubbles, Drops, and Particles. Technical Report, Academic Press

42. Antal SP, Lahey RT, Flaherty JE (1991) Analysis of phase distribution in fully developed laminar bubbly two-phase flow. Int J Multiph Flow 17:635-652. doi: 10.1016/0301-9322(91)90029-3

43. Moraga FJ, Bonetto FJ, Lahey RT (1999) Lateral forces on spheres in turbulent uniform shear flow. Int J Multiph Flow 25:1321-1372. doi: 10.1016/S0301-9322(99)00045-2

44. de Bertodano M. (1991) Turbulent Bubbly Flow in a Triangular Duct. Ph.D. thesis, Rensselaer Polytechnic Institute, USA

45. Kurul N, Podowski M. (1991) on the modeling of multidimensional in boiling channels. Proc. 27th Natl. heat Transf. Conf. Minneap.

46. Ranz W., Marshall Jr W. (1952) Evaporation from drops. In: Part 1 Part 2, Chem. Eng. Prog. pp 173-180

47. Lee W. (1980) A pressure iteration scheme for two-phase flow modeling. T.N. Veziroglu (Ed.), Multiph. Transp. Fundam. React. Safety, Appl.

48. Kandlikar SG (1990) A general correlation for saturated two-phase flow boiling heat transfer inside horizontal and vertical tubes. J Heat Transfer 112:219-228. doi: 10.1115/1.2910348 